\title{
Reduced-Function CYP2C19 Genotype and Risk of Adverse Clinical Outcomes Among Patients Treated With Clopidogrel Predominantly for PCI: A Meta-Analysis
}

\author{
Jessica L. Mega, MD MPH ${ }^{a}$, Tabassome Simon, MD PhD ${ }^{b}$, Jean-Philippe Collet, MD PhD', \\ Jeffrey L. Anderson, MD ${ }^{d}$, Elliott M. Antman, MD ${ }^{a}$, Kevin Bliden, BS ${ }^{e}$, Christopher P. \\ Cannon, MDa ${ }^{\mathrm{a}}$, Nicolas Danchin, MD PhD ${ }^{f}$, Betti Giusti, PhDg, Paul Gurbel, MD' ${ }^{\mathrm{e}}$, Benjamin D. \\ Horne, PhD $^{d}$, Jean-Sebastian Hulot, MD PhD ${ }^{h}$, Adnan Kastrati, MD ${ }^{i}$, Gilles Montalescot, MD \\ PhD', Franz-Josef Neumann, MD ${ }^{k}$, Lei Shen, PhD', Dirk Sibbing, ${ }^{\prime} D^{i}$, P. Gabriel Steg, MD $^{m}$, \\ Dietmar Trenk, PhD $^{n}$, Stephen D. Wiviott, MD $^{a}$, and Marc S. Sabatine, MD MPH ${ }^{a}$ \\ Jessica L. Mega: jmega@partners.org; Tabassome Simon: tabassome.simon@sat.aphp.fr; Jean-Philippe Collet: jean- \\ philippe.collet@psl.aphp.fr; Jeffrey L. Anderson: Jeffrey.Anderson@imail.org; Elliott M. Antman: eantman@partners.org; \\ Kevin Bliden: Kbliden@lifebridgehealth.org; Christopher P. Cannon: cpcannon@partners.org; Nicolas Danchin: \\ nicolasdanchin@yahoo.fr; Betti Giusti: betti.giusti@unifi.it; Paul Gurbel: Pgurbel@lifebridgehealth.org; Benjamin D. Horne: \\ Benjamin.Horne@imail.org; Jean-Sebastian Hulot: jean-sebastien.hulot@psl.aphp.fr; Adnan Kastrati: \\ kastrati@dhm.mhn.de; Gilles Montalescot: gilles.montalescot@psl.aphp.fr; Franz-Josef Neumann: Franz- \\ Josef.Neumann@Herzzentrum.de; Lei Shen: shen_lei@lilly.com; Dirk Sibbing: dirk@sibbing.net; P. Gabriel Steg: \\ gabriel.steg@bch.aphp.fr; Dietmar Trenk: Dietmar.Trenk@herzzentrum.de; Stephen D. Wiviott: swiviott@partners.org; \\ Marc S. Sabatine: msabatine@partners.org \\ a TIMI Study Group, Cardiovascular Division, Department of Medicine, Brigham and Women's \\ Hospital and Harvard Medical School, Boston, MA \\ b Department of Pharmacology, Assistance Publique-Hôpitaux de Paris and Universite Pierre et \\ Marie Curie, Paris, France \\ c INSERM U-937, Institute de Cardiologie, Group Hospitalier Pitié-Salpétrière, and Universite \\ Pierre et Marie Curie, Paris, France \\ d Cardiovascular Department, Intermountain Medical Center, Murray, UT \\ e Sinai Center for Thrombosis Research, Sinai Hospital of Baltimore, Baltimore, MD \\ f Division of Coronary Artery Disease, Hopital Europeen Georges Pompidou and Universite Paris \\ Rene Descartes, Paris, France \\ g Department of Medical and Surgical Critical Care, University of Florence, Florence, Italy \\ h Institut de Cardiologie and Pharmacology Department, Pitié-Salpétrière University Hospital, \\ Paris, France
}

\footnotetext{
Author Contributions: Drs Mega and Sabatine had full access to all of the data in the study and take responsibility for the integrity of the data and the accuracy of the data analysis.

Study concept and design: Mega, Simon, Sabatine; Acquisition of data: Mega, Simon, Collet, Anderson, Antman, Bliden, Cannon, Danchin, Giusti, Gurbel, Horne, Hulot, Kastrati, Montalescot, Neumann, Shen, Sibbing, Steg, Trenk, Wiviott, Sabatine; Analysis and interpretation of data: Mega, Simon, Collet, Anderson, Antman, Bliden, Cannon, Danchin, Giusti, Gurbel, Horne, Hulot, Kastrati, Montalescot, Neumann, Shen, Sibbing, Steg, Trenk, Wiviott, Sabatine; Drafting of the manuscript: Mega, Sabatine; Critical revision of the manuscript: Simon, Collet, Anderson, Antman, Bliden, Cannon, Danchin, Giusti, Gurbel, Horne, Hulot, Kastrati, Montalescot, Neumann, Shen, Sibbing, Steg, Trenk, Wiviott; Statistical analysis: Mega, Sabatine; Supervision: Mega, Simon, Collet, Anderson, Antman, Bliden, Cannon, Danchin, Giusti, Gurbel, Horne, Hulot, Kastrati, Montalescot, Neumann, Shen, Sibbing, Steg, Trenk, Wiviott, Sabatine.

Financial Disclosures: No other authors reported any disclosures.

Role of the Sponsors: Neither the funding source for JLM nor the sponsors of the individual studies had a role in the design and conduct of the meta-analysis; collection, management, analysis, and interpretation of the meta-analysis data; and preparation, review, or approval of the manuscript.
} 
i Department of Cardiology, Deutsches Herzzentrum München, Munich, Germany

j Institut de Cardiologie, Centre Hospitalier Universitaire Pitié-Salpétrière, Paris, France

${ }^{k}$ Herz-Zentrum Bad Krozingen, Bad Krozingen, Germany

' Eli Lilly, Indianapolis, IN

m INSERM U-698, Universite Paris 7, and Hopital Bichat Assistance Publique, Paris, France

n Department of Clinical Pharmacology, Herz-Zentrum Bad Krozingen, Bad Krozingen, Germany

\section{Abstract}

Content-Clopidogrel, one of the most commonly prescribed medications, is a pro-drug requiring CYP450 biotransformation. Data suggest its pharmacologic effect varies based on CYP2C19 genotype, but there is uncertainty regarding the clinical risk imparted by specific genotypes.

Objective-In patients treated with clopidogrel, to define the risk of major adverse cardiovascular outcomes among carriers of one ( $26 \%$ prevalence in whites) and carriers of two ( $\sim 2 \%$ prevalence in whites) reduced-function $C Y P 2 C 19$ variants.

Data Sources and Study Selection-A literature search was conducted (January 2000August 2010) of the MEDLINE, Cochrane, and EMBASE databases. Genetic studies were included where clopidogrel was initiated in predominantly invasively managed patients in a manner consistent with the current guideline recommendations and where clinical outcomes were ascertained.

Data Extraction-Investigators from nine studies evaluating CYP2C19 genotype and clinical outcomes in patients treated with clopidogrel contributed the relevant hazard ratios (HRs) and their 95\% confidence intervals (CI) for specific cardiovascular outcomes by genotype.

Results-Among 9685 patients [91.3\% of whom underwent percutaneous coronary intervention (PCI) and 54.5\% of whom had an acute coronary syndrome (ACS)], 863 experienced the composite endpoint of cardiovascular death, myocardial infarction, or stroke; 84 patients had stent thrombosis among the 5894 evaluated for such. Overall, $71.5 \%$ were non-carriers, $26.3 \%$ had one, and $2.2 \%$ had two CYP2C19 reduced-function alleles. A significantly increased risk of the composite endpoint was evident in both carriers of one (HR 1.55, 95\% CI 1.11-2.27, P=0.01) and two (HR 1.76, 95\% CI 1.24-2.50, P=0.002) CYP2C19 reduced-function alleles. Similarly, there was a significantly increased risk of stent thrombosis in both carriers of one (HR 2.67, 95\% CI 1.69-4.22, $\mathrm{P}<0.0001$ ) and two (HR 3.97, 95\% CI 1.75-9.02, $\mathrm{P}=0.001$ ) CYP2C19 reduced-function alleles.

Conclusion-Among patients treated with clopidogrel for PCI, carriage of even one reducedfunction $C Y P 2 C 19$ allele appears to be associated with a significantly increased risk of major adverse cardiovascular events, particularly stent thrombosis.

\section{Introduction}

Clopidogrel blocks the $\mathrm{P} 2 \mathrm{Y}_{12}$ ADP receptor on platelets and has been shown to reduce cardiovascular events in patients presenting with an acute coronary syndrome (ACS), particularly in those undergoing percutaneous coronary intervention (PCI).1, 2 However, there is a large degree of inter-individual variability in the pharmacodynamic response to clopidogrel.3 One source of the variability is the metabolism of clopidogrel, which is a prodrug requiring biotransformation to generate its active metabolite. Cytochrome P-450 (CYP) isoenzymes, specifically CYP2C19,4 play a key role in clopidogrel metabolism and carriers 
of reduced-function genetic variants in CYP2C19 have lower active clopidogrel metabolite levels and diminished platelet inhibition.5

Based in part on a pharmacokinetic and pharmacodynamic study in 40 healthy subjects, the United States Food and Drug Administration (US FDA) announced a boxed warning on Plavix (clopidogrel) stating that the drug has a diminished effect in individuals based on their CYP2C19 genotype, specifically in those who harbor two CYP2C19 reduced-function alleles.6, 7 Yet, there is not consensus as to whether the diminished pharmacologic response translates into worse clinical outcomes and whether the proposed increased risk of adverse cardiovascular outcomes requires two CYP2C19 reduced-function alleles (present in approximately $2 \%$ of the white population) or can be seen with just one (present in approximately $26 \%$ of the white population). 8

Individual clopidogrel pharmacogenetic studies have reported somewhat divergent results, and the confidence intervals corresponding to the hazard ratios for clinical events across different genotypes are sufficiently wide so as to not be able to address reliably the aforementioned issues. Moreover, to date, a number of studies have not generated data separately for carriers of one and for carriers of two reduced-function CYP2C19 alleles. Therefore, to define the risk of major adverse cardiovascular events in carriers of one and in carriers of two reduced-function CYP2C19 alleles, the investigators for each participating study agreed to perform a collaborative meta-analysis. In totality, we were able to examine the association of CYP2C19 genotype and clinical outcomes in 9685 patients who initiated guideline-recommended treatment with clopidogrel, predominantly for PCI.

\section{Methods}

\section{Data Sources and Study Selection Criteria}

A computerized literature search was conducted from January 2000 through August 2010 of the MEDLINE, Cochrane, and EMBASE databases by using search terms that included clopidogrel and CYP2C19. In addition, experts in the field were contacted and abstracts from major cardiology meetings were reviewed. The meta-analysis included studies (both cohort studies and clinical trials) where clopidogrel was initiated in predominantly invasively managed patients in a manner consistent with the current guideline recommendations.1, 2 Studies were excluded if they did not include clinical outcomes measurements.

A total of 31 studies were identified as potentially relevant and were screened for inclusion (Supplemental Table 1). Of these studies, 22 were subsequently excluded because they only provided pharmacodynamic or pharmacokinetic data (ie, no clinical outcomes data); data could not be extracted from what was presented in the main manuscript; or because they included patients from different clinical populations (eg, in whom treatment with clopidogrel was not guideline indicated or who were predominantly conservatively. Of the nine studies that were eligible and invited, all investigators agreed to provide study-level data and participate in a collaborative meta-analysis.9-17 Study quality was assessed independently based on elements from the Strengthening the Reporting of Observational Studies in Epidemiology (STROBE) checklist18 by two authors (JLM and MSS) with disagreements resolved by consensus.

\section{Genotype Data, End Points, and Data Compilation}

For each study, patients treated with clopidogrel were classified as carriers of zero (i.e., noncarriers or wildtype), one (i.e., heterozygotes), or two (e.g., homozygotes or compound heterozygotes) CYP2C19 (NCBI Genome build 37.1, NG_008384) reduced-function alleles. Of the reduced-function alleles, $C Y P 2 C 19 * 2$ is the most frequent variant (accounting for 
about $95 \%$ of the reduced-function allele carrier status). 11 In seven studies, patients were categorized on the basis of $C Y P 2 C 19^{*} 2$ (rs4244285) alone; $9,10,12,14^{-1} 17$ in one study, CYP2C19*2, *3 (rs4986893), *4 (rs28399504), and *5 (rs56337013);13 and in one study CYP2C19*2, *3, *4, *5, and *8 (rs41291556) (Supplemental Methods). 11

The investigators for each participating study provided the incidence of cardiovascular death, myocardial infarction, and ischemic stroke, as well as the composite of these end points across $C Y P 2 C 19$ genotypes in 9685 individuals. Investigators provided the hazard ratios (HRs) and 95\% confidence intervals (CIs) for these end points for carriers of at least one, only one, or two CYP2C19 reduced-function alleles compared with non-carriers, with adjusted hazard ratios provided based on the investigators' determination of the need to do so in their main publication. Additionally, six of the nine studies evaluated stent thrombosis, and thus analogous data pertaining to the risk of definite or probable stent thrombosis, as defined by the Academic Research Consortium (ARC) criteria, 19 were provided for 5894 subjects.10-12, $14^{-} 16$ Outcomes were collected from 0 days to end of follow-up, as well as from 0 to 30 days and 31 days to end of follow-up. See Supplemental Methods for studyspecific details. All of the provided data were verified by each of the participating investigators.

\section{Statistical Analyses}

We performed a meta-analysis combining HRs for each study using a random-effects model which considers both within-study and between-study variation (given the differences in study populations characteristics and clopidogrel dosing and therefore the potential differences in the pharmacogenetic association) with weighting based on inverse variance. 20 Results are presented as HRs with their 95\% CIs. Heterogeneity of risk was diagnosed using the $\mathrm{Q}$ statistic and the degree assessed using the $\mathrm{I}^{2}$ measure (which reflects the percentage of the total variability due to between-study heterogeneity versus within study variability). If heterogeneity was found, we then performed sensitivity analyses, serially excluding studies to determine the source. Additionally, sensitivity analyses were conducted examining for heterogeneity on the basis of ACS status and clopidogrel dosing. Comprehensive Meta Analysis version 2.2.048 was used for the analyses and a P value of $<0.05$ was set as the level of significance with no correction for multiple hypothesis testing given the interrelatedness of the hypotheses.

\section{Results}

Overall, 9685 patients from nine studies contributed to the cardiovascular death, myocardial infarction, or stroke analysis (Table 1). The average age of patients was 64.2 years and 7204 patients (74.4\%) were male. A total of 8847 (91.3\%) patients underwent PCI and 5278 $(54.5 \%)$ had an acute coronary syndrome. There were 6923 patients $(71.5 \%)$ with no CYP2C19 reduced-function alleles (i.e., non-carriers or wildtype), 2544 (26.3\%) with one CYP2C19 reduced-function allele (i.e., heterozygotes), and 218 (2.2\%) with two CYP2C19 reduced-function alleles (e.g., homozygotes or compound heterozygotes). There were no significant differences in baseline characteristics across genotypes (Table 2). Six studies included stent thrombosis as an endpoint, and thus 5894 stented patients were included in the stent thrombosis analyses. In this subset, there were 4220 patients $(71.6 \%)$ with no CYP2C19 reduced-function alleles, 1535 (26.0\%) with one CYP2C19 reduced-function allele, and $139(2.4 \%)$ with two $C Y P 2 C 19$ reduced-function alleles.

\section{Cardiovascular Death, MI, or Stroke by CYP2C19 Genotype}

Overall, 863 of the 9685 patients experienced the composite endpoint of cardiovascular death, myocardial infarction, or ischemic stroke. Carriers of one or two reduced-function 
CYP2C19 alleles versus non-carriers had a significantly increased risk of the composite endpoint (HR 1.57, 95\% CI 1.13-2.16, P=0.006, Figure 1, Panel A). In terms of individual endpoints, 272 patients died of a cardiovascular cause, 575 had a non-fatal myocardial infarction, and 68 had a non-fatal stroke. There was directionally consistent risk for of all the components of the composite endpoint associated with carriage of one or two reducedfunction $C Y P 2 C 19$ alleles. Specifically, for cardiovascular death the HR was 1.84 (95\% CI 1.03-3.28, $\mathrm{P}=0.041)$, for non-fatal myocardial infarction the HR was $1.45(95 \% \mathrm{CI}$ 1.09-1.92, $\mathrm{P}=0.010)$, and for stroke the HR was 1.73 (95\% CI 0.68-4.38, $\mathrm{P}=0.25$ ).

\section{Risk in Carriers of One and Two Reduced-Function CYP2C19 Alleles}

Compared with CYP2C19 non-carriers, there was a significantly increased risk of cardiovascular death, myocardial infarction, or stroke in the $26.3 \%$ of the overall study population who carried only one $C Y P 2 C 19$ reduction-function allele (HR $1.55,95 \% \mathrm{CI}$ 1.11-2.17, $\mathrm{P}=0.01$, Figure 1, Panel B). Similarly, there was a significantly increased risk of cardiovascular death, myocardial infarction, or stroke in the $2.2 \%$ of the overall study population who carried two CYP2C19 reduction-function alleles (HR 1.76, 95\% CI 1.24-2.50, $\mathrm{P}=0.002$, Figure 1, Panel C).

\section{Stent Thrombosis Outcomes by CYP2C19 Genotype}

Overall, stent thrombosis occurred in 84 of the 5894 patients who had a stent implanted and were followed for stent thrombosis. Carriers of one or two reduced-function CYP2C19 alleles versus non-carriers had a significantly increased risk of stent thrombosis (HR 2.81, 95\% CI 1.81-4.37, P<0.00001, Figure 2, Panel A). Analogous to the observations for cardiovascular death, myocardial infarction, or stroke, both carriers of only one CYP2C19 reduced-function allele (HR 2.67, 95\% CI 1.69-4.22, P<0.0001, Figure 2, Panel B) and carriers of two alleles (HR 3.97, 95\% CI 1.75-9.02, P=0.001, Figure 2, Panel C) were at significantly increased risk of stent thrombosis when compared with CYP2C19 non-carriers.

\section{Timing of Events}

In landmark analyses, carriers of one or two reduced-function CYP2C19 alleles versus noncarriers had a HR of 1.36 (95\% CI 1.11-1.65) for cardiovascular death, myocardial infarction, or stroke over the first 30 days and a HR of 1.61 (95\% CI 0.88-2.95) from 31 days until the end of follow-up (Figure 3). For stent thrombosis, carriers of one or two reduced-function CYP2C19 alleles versus non-carriers had a HR of 2.94 (95\% CI 1.75-4.94) over the first 30 days and a HR of 2.80 (95\% CI 0.83-9.38) from 31 days until the end of follow-up (Figure 3).

\section{Exploring Heterogeneity between Studies and Among Subgroups}

There was evidence of heterogeneity for the endpoint of cardiovascular death, myocardial infarction, or stroke when comparing carriers of only one $C Y P 2 C 19$ reduced-function allele with non-carriers $\left(\mathrm{Q}=29.22, \mathrm{P}<0.001\right.$ for heterogeneity; $\left.\mathrm{I}^{2}=73 \%\right)$. Exclusion of two studies, FAST-MI and AFIJI, resulted in resolution of heterogeneity $(\mathrm{Q}=4.63, \mathrm{P}=0.59$ for heterogeneity, $\mathrm{I}^{2}=0 \%$ ). The characteristics of patients in these two studies were similar to those in the other seven studies, and the HRs for FAST-MI and AFIJI fell on either side of the summary HR. After excluding these studies, the summary HR for carriers of only one CYP2C19 reduction-function allele was 1.42 (95\% CI 1.19-1.69), which was similar to the HR calculated from analyzing all nine studies. There was no evidence of statistically significant heterogeneity for the endpoint of cardiovascular death, myocardial infarction, or stroke when comparing carriers of two $C Y P 2 C 19$ reduced-function alleles with non-carriers $(\mathrm{Q}=5.87, \mathrm{P}=0.44$ for heterogeneity), nor was there any significant heterogeneity in the stent thrombosis analyses (carriers of one CYP2C19 reduced function allele vs. non-carriers: 
$\mathrm{Q}=4.44, \mathrm{P}=0.49$ for heterogeneity; carriers of two $C Y P 2 C 19$ reduced function alleles vs. non-carriers: $\mathrm{Q}=5.77, \mathrm{P}=0.22$ for heterogeneity).

There was no evidence of heterogeneity for the endpoint of cardiovascular death, myocardial infarction, or stroke or for stent thrombosis across studies that had all, some, or no patients with ACS $(\mathrm{Q}=3.82, \mathrm{P}=0.15$ and $\mathrm{Q}=1.26, \mathrm{P}=0.53$, respectively) or across studies that used only $300 \mathrm{mg}, 300$ or $600 \mathrm{mg}$, or $\geq 600 \mathrm{mg}$ of clopidogrel as the loading dose $(\mathrm{Q}=1.61$, $\mathrm{P}=0.45$ and $\mathrm{Q}=0.25, \mathrm{P}=0.88$, respectively).

\section{Comment}

By performing a collaborative meta-analysis with data by genotype, we found that among patients treated with clopidogrel predominantly for PCI, carriage of even one reducedfunction $C Y P 2 C 19$ allele is associated with an increased risk of adverse cardiovascular events, particularly stent thrombosis. Thus, CYP2C19 genetic information identifies approximately $30 \%$ or more of the population who may be less likely to be protected from recurrent ischemic events after PCI despite treatment with standard doses of clopidogrel.

Guidelines about caring for patients with CYP2C19 polymorphisms are starting to be developed at national levels.6, 7, 21 For example, in March of 2010, the US FDA issued a warning suggesting that there can be a diminished effect of standard doses of clopidogrel in CYP2C19 poor metabolizers, who were defined as individuals with two reduced-function CYP2C19 alleles. The proportion of the population harboring two reduced-function CYP2C19 alleles is approximately $2 \%$ for whites, $4 \%$ for blacks, and $14 \%$ for Chinese. 8 The FDA referenced a crossover study of 40 healthy subjects, who were treated with $300 \mathrm{mg}$ of clopidogrel followed by $75 \mathrm{mg}$ per day and with $600 \mathrm{mg}$ followed by $150 \mathrm{mg}$ per day. The study found that individuals with two reduced-function CYP2C19 alleles, as compared with carriers of one or none, exhibited substantially decreased active drug metabolite levels and inhibition of platelet aggregation. However, it should be noted that a number of other pharmacokinetic and pharmacodynamic studies have also found that individuals (including both healthy persons and, perhaps more germane, patients with coronary artery disease) who carry even one reduced-function $C Y P 2 C 19$ allele have a blunted pharmacologic response to treatment with clopidogrel, albeit less pronounced than the effect seen among carriers of two reduced-function alleles.10, $22-29$ Thus, it is plausible that carriers of even one CYP2C19 reduced-function allele as compared with non-carriers would be at increased risk of adverse cardiovascular events in the setting of treatment with standard doses of clopidogrel.

The totality of the pharmacologic data support the findings of our meta-analysis on clinical outcomes, which suggest that patients undergoing PCI treated with standard doses of clopidogrel who have either one or two reduced-function CYP2C19 alleles are at increased risk for major adverse cardiovascular events. The observed HRs for adverse cardiovascular events of 1.55 (for carriers of one CYP2C19 reduced function allele vs. non-carriers) and 1.76 (for carriers of two CYP2C19 reduced function alleles vs. non-carriers) are plausible. The meta-analysis population predominantly underwent PCI, a setting in which dual antiplatelet therapy as compared with aspirin monotherapy results in risk reductions up to 75-85\%.30 In such a situation, even partial reductions in the antiplatelet effect of clopidogrel could translate into a several fold increase in the risk of major adverse cardiovascular outcomes. As would be expected, the point estimates for the hazard ratios were numerically higher in patients who carried two rather than one reduced-function alleles, but with overlapping confidence intervals. Moreover, the pharmacogenetic effect was more pronounced for the specific outcome of stent thrombosis than for the broader outcome of cardiovascular death, myocardial infarction, or stroke. This observation logically follows 
from the more pronounced risk reduction that has been documented with thienopyridines on the former versus the latter outcome.30, 31

Three genetic studies not included in our meta-analysis warrant comment as their results highlight the influence of the clinical setting on the relationship between $C Y P 2 C 19$ genotype, clopidogrel, and clinical outcomes. Specifically, the most significant pharmacogenetic effect appears to be seen in patients treated with clopidogrel for PCI. In the genetic substudy from the PLATO trial approximately two-thirds of patients underwent PCI. Although the required data from this substudy could not be incorporated directly into our meta-analysis due to the manner in which their published data were presented (ie, only presenting results by carrier state rather than by number of alleles), at 30 days the rate of cardiovascular death, myocardial infarction, or stroke among patients treated with clopidogrel was 5.7\% in carriers of 1 or 2 reduced-function CYP2C19 alleles and $3.8 \%$ in noncarriers $(\mathrm{P}=.028)$, which represents a $37 \%$ increased risk of events-similar to the current metaanalytic point estimate.32 In landmark analyses, the investigators did not observe any increased risk after 30 days, and the rate of cardiovascular death, myocardial infarction, or stroke by 12 months among patients treated with clopidogrel was $11.2 \%$ in carriers of a CYP2C19 reduced-function allele and $10.0 \%$ in non-carriers. In a sensitivity analysis adding data from the PLATO genetic substudy (estimating an HR through 12 months of 1.12 for carriers vs. non-carriers of a $C Y P 2 C 19$ reduced-function allele) to the other nine studies in the meta-analysis, the estimated risk among patients treated with clopidogrel of cardiovascular death, myocardial infarction, or stroke associated with carriage of a CYP2C19 reduced-function allele was largely unchanged (HR 1.43, 95\% CI 1.11-1.84).

Patients in the genetic substudy from the CURE trial were conservatively managed with only $15.5 \%$ undergoing PCI with stenting. In this setting, the investigators observed no hazard associated with carriage of a CYP2C19 reduced-function allele among patients treated with clopidogrel (HR 0.86, 95\% CI 0.63-1.17).33 Notably, in contrast to the 75-85\% risk reduction resulting from the addition of a thienopyridine in patients who undergo stenting,30 in conservatively managed patients, treatment with clopidogrel is associated with only an approximately $20 \%$ reduction in cardiovascular death, MI, or stroke.31 Moreover, carriage of a CYP2C19 reduced-function allele does not completely negate the effects of clopidogrel, but rather is associated with active metabolite and platelet inhibition levels roughly $25-33 \%$ less than what is observed in non-carriers. 11 Taking these factors into account, one would expect carriage of a CYP2C19 reduced-function allele to confer only a $10-15 \%$ increase in risk in predominantly conservatively managed patients such as those in the genetic substudy of CURE, a value that falls within their observed 95\% CI. Lastly, in the CHARISMA trial, clopidogrel was not given in a manner consistent with the current guideline recommendations, and notably not all patients had established coronary disease, of those with a prior myocardial infarction the median time from that myocardial infarction to inclusion in the study was approximately two years, and only $22 \%$ underwent prior PCI. In this setting, no risk was observed with carriage of $C Y P 2 C 19$ reduced-function alleles among patients treated with clopidogrel in the genetic substudy of the CHARISMA trial,34 but as treatment with clopidogrel did not reduce adverse cardiovascular events in the overall population, 35 no pharmacogenetic interaction would be expected. In a further sensitivity analysis adding data from the CURE genetic substudy (see above) and the CHARISMA genetic substudy (estimating a HR of 1.25 for carriers vs. non-carriers of a CYP2C19 reduced-function allele) to the PLATO data and the other nine studies in the meta-analysis, there appears to remain a significant association between carriage of a CYP2C19 reducedfunction allele and cardiovascular death, myocardial infarction, or stroke (HR 1.32, 95\% CI 1.07-1.63) in the setting of treatment with clopidogrel. 
The pharmacokinetic and pharmacodynamic literature supports the notion that the mechanism underlying the observed association between CYP2C19 reduced-function variants and clinical outcomes is reduced bioactivation of clopidogrel into its active metabolite. Nonetheless, it has been discussed whether variants in CYP2C19 could themselves be associated with an increase in adverse cardiovascular events, regardless of treatment with clopidogrel. To that end, in the placebo arm of CHARISMA a directionally higher hazard was observed among carriers of two reduced-function alleles versus noncarriers (HR 1.82, 95\% CI 0.74-4.65).34 In contrast, in the CURE genetic substudy, among subjects in the placebo arm, the rate of adverse cardiovascular events was numerically lower among carriers of a reduced-function $C Y P 2 C 19$ allele (11.6\%) as compared with noncarriers (13.0\%).33 Similarly, in both CLARITY-TIMI 28 and CLEAR-PLATELETS there was no association between $C Y P 2 C 19$ genotype and adverse cardiovascular outcomes for patients not on clopidogrel.9, 16 Furthermore, among patients in TRITON-TIMI 38 treated with prasugrel (a third-generation thienopyridine that is metabolized differently than is clopidogrel) and among patients in PLATO treated with ticagrelor (a non-thienopyridine $\mathrm{P}_{2} \mathrm{Y}_{12}$ ADP receptor blocker that does not undergo biotransformation to an active metabolite by CYP2C19), CYP2C19 genetic variants were not associated with an increased risk of clinical outcomes.32, 36 Lastly, in genome-wide association studies for incident myocardial infarction involving over 20,000 subjects, no association with CYP2C19 was found.37

Tests are available to identify a patient's CYP2C19 genotype. Although these tests are not widely used at this time, some physicians have started to employ a strategy of CYP2C19 genotyping among subjects initiating treatment with clopidogrel.38 Moving forward, pointof-care genotyping will likely be available, and this technology could further ease the implementation of CYP2C19 testing for interested clinicians and patients.39 Point-of-care testing is also available for platelet function testing. The relationship between pharmacogenetic and pharmacodynamic testing continues to be explored. In one study, CYP2C19 polymorphisms appear to account for $12 \%$ of the variability in the effect of clopidogrel, as measured using ADP-induced platelet aggregation, and environmental factors account for $<10 \%$ of the variability. 16 Compounding the complexity of the relationship, light transmittance aggregometry itself has variable reproducibility. 40 The association seen between higher platelet reactivity and adverse cardiovascular outcomes is of comparable magnitude to the pharmacogenetic findings, 41 and some, but not all studies have suggested that pharmacogenetic and platelet function testing offer independent predictive value.14, 16 Of note, it should be acknowledged that neither genotyping nor platelet function testing is a perfect discriminator of subsequent clinical outcomes, underscoring the complex, multifactorial nature of cardiovascular risk.42 Nonetheless, prospective trials of the clinical utility of incorporating genetics and platelet function testing into treatment decisions are underway.21, $43^{-} 45$

With respect to treatment options, there are some early data suggesting that increasing the dose of clopidogrel in carriers of a CYP2C19 reduced-function allele may improve the degree of platelet inhibition.7, 46-49 However, all of these studies have been small, with no study having more than 20 carriers of a CYP2C19 reduced-function allele, and with no study reporting clinical outcomes data. Larger studies that incorporate CYP2C19 genotyping and explore the influence of higher doses of clopidogrel on platelet function parameters, as well as clinical outcomes, will be useful in further assisting with therapeutic decisions. Understanding the ability to treat patients effectively with clopidogrel across CYP2C19 genotypes will be particularly important from a healthcare cost perspective, as the drug is already off patent in some countries and anticipated to go off patent in the US and others in the near future. Additionally, there are other antiplatelet agents that may serve as particularly attractive treatment options for patients with a genetically-impaired response to clopidogrel, 
such as either of the third generation $\mathrm{P}_{2} \mathrm{Y}_{12}$ ADP receptor blockers prasugrel or ticagrelor, 50, 51 neither of which appears to be influenced by polymorphisms in CYP2C19.32, 36 However, currently prasugrel is only approved by the FDA for use in ACS patients who are to be managed with PCI, and ticagrelor is not yet approved.

There are some limitations to these analyses. First, over $95 \%$ of the study population was white. Of note, though, the effects of $C Y P 2 C 19$ reduced-function alleles on platelet inhibition with clopidogrel appear to be consistent in white and non-white individuals.25, 26 Second, over $90 \%$ of the study population was treated with clopidogrel for a PCI, and, as discussed above, the impact of CYP2C19 genotype would be expected to be, and data suggest is, considerably less in patients who do not undergo PCI, where clopidogrel has more modest efficacy. Third, most of the studies included in the meta-analysis provided information only on $C Y P 2 C 19 * 2$. CYP $2 C 19 * 2$, though, is by far the most frequent variant, accounting for about $95 \%$ of the reduced-function allele carrier status and the lack of genotyping beyond the $* 2$ allele would be expected to bias towards the null, since carriers of other CYP2C19 reduced-function alleles (e.g. CYP2C19*3) were included in the noncarriers for seven of the studies. Likewise, there are other genes, not included in this metaanalysis, which may influence the response to clopidogrel. Fourth, for logistical reasons, individual patient-level data could not be combined. Comparative studies, though, have demonstrated excellent quantitative agreement between summary data and patient-level data when the same datasets are used for both analyses and the same exposures and outcomes are used, as was the case for the present meta-analysis.52 Finally, the studies contributing to this meta-analysis were generally large clinical outcomes studies in which platelet function testing was not routinely performed. As such, the meta-analysis focuses on the relationship between genotype and outcomes; other studies have highlighted the predictive value of platelet function testing. 53

In conclusion, the findings of this collaborative meta-analysis demonstrate that common genetic variants are associated with almost one in three patients not receiving ideal protection from ischemic events when treated with standard doses of clopidogrel for PCI. Given how widely clopidogrel is used to treat patients with cardiovascular disease, determination of the optimal antiplatelet treatment doses or regimens for individual patients is needed in order to appropriately tailor therapy.

\section{Supplementary Material}

Refer to Web version on PubMed Central for supplementary material.

\section{Acknowledgments}

JL Mega reports receiving research grant funding from Bayer Healthcare, Bristol-Myers Squibb, Daiichi Sankyo, Eli Lilly, Johnson \& Johnson, Sanofi-Aventis; consulting fees from AstraZeneca, Bristol-Myers Squibb, SanofiAventis; and lecture fees from Novartis. T Simon reports receiving research grant funding from Servier, Pfizer, Daiichi Sankyo, Eli Lilly, Sanofi -Aventis, AstraZeneca, Caisse d'Assurance Maladie and consulting fees from Eli Lilly, Daiichi Sankyo, Sanofi -Aventis, Bristol-Myers Squibb, AstraZeneca. JP Collet reports receiving research grant funding from Bristol-Myers Squibb, Sanofi-Aventis, Eli Lilly, Guerbet Medical, Medtronic, Boston Scientific, Cordis, Stago, Centocor, Fondation de France, INSERM, Federation Francaise de Cardiologie, Societé Francaise de Cardiologie; lecture fees from Bristol-Myers Squibb, Sanofi -Aventis, Eli Lilly; and consulting fees from Sanofi-Aventis, Eli Lilly, Bristol-Myers Squibb. JL Anderson reports receiving consulting fees from BristolMyers Squibb, Sanofi-Aventis. EM Antman reports receiving research grant funding from Daiichi Sankyo, Eli Lilly; consulting fees from Sanofi-Aventis; and, lecture fees from Eli Lilly, Sanofi-Aventis. CP Cannon reports receiving research grant funding from Accumetrics, AstraZeneca, GlaxoSmithKline, Intekrin Therapeutics, Merck, Takeda; serves on the advisory board for Bristol-Myers Squibb/Sanofi, Novartis, Alnylam and donates the funds to charity; and is a clinical advisor with equity in Automedics Medical Systems. N Danchin reports receiving research grant funding from Astra-Zeneca, Eli Lilly, Merck, Novartis, Pfizer, Sanofi-Aventis, Servier, and The Medicines Company; lecture fees from AstraZeneca, Boehringer-Ingelheim, Bristol-Myers Squibb, Glaxo Smith Kline, Menarini, Merck-Serono, MSD-Schering Plough, Servier, and Sanofi-Aventis; and consulting fees from 
AstraZeneca, Eli Lilly, Novo, Sanofi-Aventis, and Servier. P Gurbel reports receiving research grant funding from Schering Plough, Millennium, AstraZeneca, Bayer, Haemonetics, Medtronic, Boston Scientific and honoraria from Schering Plough, AstraZeneca, Bayer, Portola, Medtronic. JS Hulot reports receiving research grant support from Fondation de France, INSERM, Federation Francaise de Cardiologie, Biotronik, Medco Research Institute; consulting fees from Biotronik, Medco Health Solutions; and, lecture fees from Sanofi-Aventis, Daiichi Sankyo, Eli Lilly, Bristol-Myers Squibb. G Montalescot reports receiving research grant funding from Abbott Vascular, BristolMyers Squibb, Boston Scientific, Centocor, Cordis, Eli-Lilly, Fédération Française de Cardiologie, Fondation de France, Guerbet Medical, INSERM, ITC Edison, Medtronic, Pfizer, Sanofi-Aventis, Societe Francaise de Cardiologie, Stago; consulting fees from Astra-Zeneca, Bayer, Boehringer-Ingelheim, Bristol-Myers Squibb, Daichi-Sankyo, Eisai, Eli-Lilly, Menarini, Novartis, Pfizer, Portola, Sanofi-Aventis Group, Schering-Plough, The Medicines Company; and lecture fees from Abbott Vascular, Accumetrics, AstraZeneca, Bristol-Myers Squibb, Cordis, Daiichi-Sankyo, Eli Lilly, GlaxoSmithKline, Menarini, Merck Sharpe \& Dohme, Pfizer, Sanofi-Aventis, Schering-Plough. L Shen reports being employed and having ownership interest in Eli Lilly. D Sibbing reports receiving consulting fees from Eli Lilly and lecture fees from Dynabyte and The Medicines Company. PG Steg reports receiving research grant funding from Servier; consulting fees from Astellas, AstraZeneca, Bayer, Boehringer-Ingelheim, Bristol-Myers Squibb, Daichii Sankyo/Lilly, GlaxoSmithKline, Medtronic, Merck, Otsuka, Pfizer, Roche, Sanofi-Aventis, Servier, The Medicines Company; and is a stockholder in Aterovax. D Trenk reports receiving research grant support from Eli Lilly; consulting fees from Eli Lilly, Daiichi Sankyo, AstraZeneca; and lecture fees from Eli Lilly and Daichii Sankyo. SD Wiviott reports receiving research grant funding from Eli Lilly, Daiichi Sankyo, Merck-Schering Plough; honoraria from AstraZeneca, Novartis; Eli Lilly, Daiichi Sankyo; and consulting fees from AstraZeneca, Sanofi-Aventis, Portola, Arena. MS Sabatine reports receiving research grant funding from AstraZeneca, Sanofi-Aventis; honoraria from Bristol-Myers Squibb, Eli Lilly; and consulting fees from AstraZeneca.

Funding Support: Dr. Mega is supported in part by grant K99/R00 HL098461-01 from the National Institutes of Health.

\section{References}

1. Kushner FG, Hand M, Smith SC Jr, King SB 3rd, Anderson JL, Antman EM, Bailey SR, Bates ER, Blankenship JC, Casey DE Jr, Green LA, Hochman JS, Jacobs AK, Krumholz HM, Morrison DA, Ornato JP, Pearle DL, Peterson ED, Sloan MA, Whitlow PL, Williams DO. 2009 focused updates: ACC/AHA guidelines for the management of patients with ST-elevation myocardial infarction (updating the 2004 guideline and 2007 focused update) and ACC/AHA/SCAI guidelines on percutaneous coronary intervention (updating the 2005 guideline and 2007 focused update) a report of the American College of Cardiology Foundation/American Heart Association Task Force on Practice Guidelines. J Am Coll Cardiol. 2009; 54(23):2205-2241. [PubMed: 19942100]

2. Anderson JL, Adams CD, Antman EM, Bridges CR, Califf RM, Casey DE Jr, Chavey WE 2nd, Fesmire FM, Hochman JS, Levin TN, Lincoff AM, Peterson ED, Theroux P, Wenger NK, Wright RS, Smith SC Jr, Jacobs AK, Halperin JL, Hunt SA, Krumholz HM, Kushner FG, Lytle BW, Nishimura R, Ornato JP, Page RL, Riegel B. ACC/AHA 2007 guidelines for the management of patients with unstable angina/non ST-elevation myocardial infarction: a report of the American College of Cardiology/American Heart Association Task Force on Practice Guidelines (Writing Committee to Revise the 2002 Guidelines for the Management of Patients With Unstable Angina/ Non ST-Elevation Myocardial Infarction): developed in collaboration with the American College of Emergency Physicians, the Society for Cardiovascular Angiography and Interventions, and the Society of Thoracic Surgeons: endorsed by the American Association of Cardiovascular and Pulmonary Rehabilitation and the Society for Academic Emergency Medicine. Circulation. 2007; 116(7):e148-304. [PubMed: 17679616]

3. Angiolillo DJ, Fernandez-Ortiz A, Bernardo E, Alfonso F, Macaya C, Bass TA, Costa MA. Variability in individual responsiveness to clopidogrel: clinical implications, management, and future perspectives. J Am Coll Cardiol. 2007; 49(14):1505-1516. [PubMed: 17418288]

4. Kazui M, Nishiya Y, Ishizuka T, Hagihara K, Farid NA, Okazaki O, Ikeda T, Kurihara A. Identification of the human cytochrome P450 enzymes involved in the two oxidative steps in the bioactivation of clopidogrel to its pharmacologically active metabolite. Drug Metab Dispos. 2009; 38(1):92-99. [PubMed: 19812348]

5. Giusti B, Gori AM, Marcucci R, Saracini C, Vestrini A, Abbate R. Determinants to optimize response to clopidogrel in acute coronary syndrome. Pharmacogenetics and personalized medicine. 2010; 3:33-50. 
6. [July 15, 2010]. http://www.fda.gov/Drugs/DrugSafety/PostmarketDrugSafetyInformationforPatientsandProviders/ ucm203888.htm

7. [July 15, 2010]. http://products.sanofi-aventis.us/PLAVIX/PLAVIX.html

8. Desta Z, Zhao X, Shin JG, Flockhart DA. Clinical significance of the cytochrome P450 2C19 genetic polymorphism. Clin Pharmacokinet. 2002; 41(12):913-958. [PubMed: 12222994]

9. Mega JL, Thakuria JV, Cannon CP, Sabatine MS. Sequence variations in CYP metabolism genes and cardiovascular outcomes following treatment with clopidogrel: insights from the CLARITYTIMI 28 genomic study. J Am Coll Cardiol. 2008; 51(Suppl A):206A.

10. Trenk D, Hochholzer W, Fromm MF, Chialda LE, Pahl A, Valina CM, Stratz C, Schmiebusch P, Bestehorn HP, Buttner HJ, Neumann FJ. Cytochrome P450 2C19 681G>A polymorphism and high on-clopidogrel platelet reactivity associated with adverse 1-year clinical outcome of elective percutaneous coronary intervention with drug-eluting or bare-metal stents. J Am Coll Cardiol. 2008; 51(20):1925-1934. [PubMed: 18482659]

11. Mega JL, Close SL, Wiviott SD, Shen L, Hockett RD, Brandt JT, Walker JR, Antman EM, Macias W, Braunwald E, Sabatine MS. Cytochrome p-450 polymorphisms and response to clopidogrel. N Engl J Med. 2009; 360(4):354-362. [PubMed: 19106084]

12. Collet JP, Hulot JS, Pena A, Villard E, Esteve JB, Silvain J, Payot L, Brugier D, Cayla G, Beygui F, Bensimon G, Funck-Brentano C, Montalescot G. Cytochrome P450 2C19 polymorphism in young patients treated with clopidogrel after myocardial infarction: a cohort study. Lancet. 2009; 373(9660):309-317. [PubMed: 19108880]

13. Simon T, Verstuyft C, Mary-Krause M, Quteineh L, Drouet E, Meneveau N, Steg PG, Ferrieres J, Danchin N, Becquemont L. Genetic determinants of response to clopidogrel and cardiovascular events. N Engl J Med. 2009; 360(4):363-375. [PubMed: 19106083]

14. Giusti B, Gori AM, Marcucci R, Saracini C, Sestini I, Paniccia R, Buonamici P, Antoniucci D, Abbate R, Gensini GF. Relation of cytochrome P450 2C19 loss-of-function polymorphism to occurrence of drug-eluting coronary stent thrombosis. Am J Cardiol. 2009; 103(6):806-811. [PubMed: 19268736]

15. Sibbing D, Stegherr J, Latz W, Koch W, Mehilli J, Dorrler K, Morath T, Schomig A, Kastrati A, von Beckerath N. Cytochrome P450 2C19 loss-of-function polymorphism and stent thrombosis following percutaneous coronary intervention. Eur Heart J. 2009; 30(8):916-922. [PubMed: 19193675]

16. Shuldiner AR, O'Connell JR, Bliden KP, Gandhi A, Ryan K, Horenstein RB, Damcott CM, Pakyz R, Tantry US, Gibson Q, Pollin TI, Post W, Parsa A, Mitchell BD, Faraday N, Herzog W, Gurbel PA. Association of cytochrome P450 2C19 genotype with the antiplatelet effect and clinical efficacy of clopidogrel therapy. JAMA. 2009; 302(8):849-857. [PubMed: 19706858]

17. Anderson JL, Mower CP, Horne BD, Muhlestein JB, Park JL, Bair TL, Carlquist JF. Carriage of the CYP2C19*2 allele increases one-year risk of myocardial infarction among recipients of drugeluting stents treated with clopidogrel. J Am Coll Cardiol. 2009; 53 A(10):A27.

18. von Elm E, Altman DG, Egger M, Pocock SJ, Gotzsche PC, Vandenbroucke JP. Strengthening the Reporting of Observational Studies in Epidemiology (STROBE) statement: guidelines for reporting observational studies. BMJ. 2007; 335(7624):806-808. [PubMed: 17947786]

19. Mauri L, Hsieh WH, Massaro JM, Ho KK, D'Agostino R, Cutlip DE. Stent thrombosis in randomized clinical trials of drug-eluting stents. N Engl J Med. 2007; 356(10):1020-1029. [PubMed: 17296821]

20. DerSimonian R, Laird N. Meta-analysis in clinical trials. Controlled Clinical Trials. 1986; 7(3): 177-188. [PubMed: 3802833]

21. Holmes DR Jr, Dehmer GJ, Kaul S, Leifer D, O'Gara PT, Stein CM. ACCF/AHA Clopidogrel Clinical Alert: Approaches to the FDA "Boxed Warning": A Report of the American College of Cardiology Foundation Task Force on Clinical Expert Consensus Documents and the American Heart Association. Circulation. 122(5):537-557. [PubMed: 20585015]

22. Hulot JS, Bura A, Villard E, Azizi M, Remones V, Goyenvalle C, Aiach M, Lechat P, Gaussem P. Cytochrome P450 2C19 loss-of-function polymorphism is a major determinant of clopidogrel responsiveness in healthy subjects. Blood. 2006; 108(7):2244-2247. [PubMed: 16772608] 
23. Fontana P, Hulot JS, De Moerloose P, Gaussem P. Influence of CYP2C19 and CYP3A4 gene polymorphisms on clopidogrel responsiveness in healthy subjects. J Thromb Haemost. 2007; 5(10):2153-2155. [PubMed: 17697139]

24. Brandt JT, Close SL, Iturria SJ, Payne CD, Farid NA, Ernest CS 2nd, Lachno DR, Salazar D, Winters KJ. Common polymorphisms of CYP2C19 and CYP2C9 affect the pharmacokinetic and pharmacodynamic response to clopidogrel but not prasugrel. J Thromb Haemost. 2007; 5(12): 2429-2436. [PubMed: 17900275]

25. Kim KA, Park PW, Hong SJ, Park JY. The effect of CYP2C19 polymorphism on the pharmacokinetics and pharmacodynamics of clopidogrel: a possible mechanism for clopidogrel resistance. Clin Pharmacol Ther. 2008; 84(2):236-242. [PubMed: 18323861]

26. Umemura K, Furuta T, Kondo K. The common gene variants of CYP2C19 affect pharmacokinetics and pharmacodynamics in an active metabolite of clopidogrel in healthy subjects. J Thromb Haemost. 2008; 6(8):1439-1441. [PubMed: 18532997]

27. Giusti B, Gori AM, Marcucci R, Saracini C, Sestini I, Paniccia R, Valente S, Antoniucci D, Abbate R, Gensini GF. Cytochrome P450 2C19 loss-of-function polymorphism, but not CYP3A4 IVS10 + 12G/A and P2Y12 T744C polymorphisms, is associated with response variability to dual antiplatelet treatment in high-risk vascular patients. Pharmacogenet Genomics. 2007; 17(12): 1057-1064. [PubMed: 18004210]

28. Frere C, Cuisset T, Morange PE, Quilici J, Camoin-Jau L, Saut N, Faille D, Lambert M, JuhanVague I, Bonnet JL, Alessi MC. Effect of cytochrome p450 polymorphisms on platelet reactivity after treatment with clopidogrel in acute coronary syndrome. Am J Cardiol. 2008; 101(8):10881093. [PubMed: 18394438]

29. Varenhorst C, James S, Erlinge D, Brandt JT, Braun OO, Man M, Siegbahn A, Walker J, Wallentin L, Winters KJ, Close SL. Genetic variation of CYP2C19 affects both pharmacokinetic and pharmacodynamic responses to clopidogrel but not prasugrel in aspirin-treated patients with coronary artery disease. Eur Heart J. 2009; 30(14):1744-1752. [PubMed: 19429918]

30. Leon MB, Baim DS, Popma JJ, Gordon PC, Cutlip DE, Ho KK, Giambartolomei A, Diver DJ, Lasorda DM, Williams DO, Pocock SJ, Kuntz RE. A clinical trial comparing three antithromboticdrug regimens after coronary-artery stenting. Stent Anticoagulation Restenosis Study Investigators. N Engl J Med. 1998; 339(23):1665-1671. [PubMed: 9834303]

31. The Clopidogrel in Unstable Angina to Prevent Recurrent Ischemic Events Trial Investigators. Effects of clopidogrel in addition to aspirin in patients with acute coronary syndromes without STsegment elevation. N Engl J Med. 2001; 345:494-502. [PubMed: 11519503]

32. Wallentin L, James S, Storey RF, Armstrong M, Barratt BJ, Horrow J, Husted S, Katus H, Steg PG, Shah SH, Becker RC. Effect of CYP2C19 and ABCB1 single nucleotide polymorphisms on outcomes of treatment with ticagrelor versus clopidogrel for acute coronary syndromes: a genetic substudy of the PLATO trial. Lancet.

33. Pare G, Mehta SR, Yusuf S, Anand SS, Connolly SJ, Hirsh J, Simonsen K, Bhatt D, Fox KAA, Eikelboom JW. Effects of CYP2C19 genotype on outcomes of clopidogrel treatment. New England Journal of Medicine.

34. Bhatt, DL.; Simonsen, KL.; Emison, ES.; Fox, KA.; Steg, PG.; Montalescot, G.; Bhakta, N.; Hacke, W.; Flather, MD.; Cacoub, P.; Creager, MA.; Berger, PB.; Steinhubl, SR.; Murugesan, G.; Kottke-Marchant, K.; Lincoff, AM.; Topol, EJ. TCT. San Francisco, CA: 2009. Charisma genomics substudy: evaluation of the CYP2C19 polymorphism in a prospective, randomized, placebo-controlled trial of chronic clopidogrel use for primary and secondary prevention.

35. Bhatt DL, Fox KA, Hacke W, Berger PB, Black HR, Boden WE, Cacoub P, Cohen EA, Creager MA, Easton JD, Flather MD, Haffner SM, Hamm CW, Hankey GJ, Johnston SC, Mak KH, Mas JL, Montalescot G, Pearson TA, Steg PG, Steinhubl SR, Weber MA, Brennan DM, Fabry-Ribaudo L, Booth J, Topol EJ. Clopidogrel and aspirin versus aspirin alone for the prevention of atherothrombotic events. N Engl J Med. 2006; 354(16):1706-1717. [PubMed: 16531616]

36. Mega JL, Close SL, Wiviott SD, Shen L, Hockett RD, Brandt JT, Walker JR, Antman EM, Macias WL, Braunwald E, Sabatine MS. Cytochrome P450 genetic polymorphisms and the response to prasugrel: relationship to pharmacokinetic, pharmacodynamic, and clinical outcomes. Circulation. 2009; 119(19):2553-2560. [PubMed: 19414633] 
37. Kathiresan S, Voight BF, Purcell S, Musunuru K, Ardissino D, Mannucci PM, Anand S, Engert JC, Samani NJ, Schunkert H, Erdmann J, Reilly MP, Rader DJ, Morgan T, Spertus JA, Stoll M, Girelli D, McKeown PP, Patterson CC, Siscovick DS, O'Donnell CJ, Elosua R, Peltonen L, Salomaa V, Schwartz SM, Melander O, Altshuler D, Merlini PA, Berzuini C, Bernardinelli L, Peyvandi F, Tubaro M, Celli P, Ferrario M, Fetiveau R, Marziliano N, Casari G, Galli M, Ribichini F, Rossi M, Bernardi F, Zonzin P, Piazza A, Yee J, Friedlander Y, Marrugat J, Lucas G, Subirana I, Sala J, Ramos R, Meigs JB, Williams G, Nathan DM, MacRae CA, Havulinna AS, Berglund G, Hirschhorn JN, Asselta R, Duga S, Spreafico M, Daly MJ, Nemesh J, Korn JM, McCarroll SA, Surti A, Guiducci C, Gianniny L, Mirel D, Parkin M, Burtt N, Gabriel SB, Thompson JR, Braund PS, Wright BJ, Balmforth AJ, Ball SG, Hall AS, Linsel-Nitschke P, Lieb W, Ziegler A, Konig I, Hengstenberg C, Fischer M, Stark K, Grosshennig A, Preuss M, Wichmann HE, Schreiber S, Ouwehand W, Deloukas P, Scholz M, Cambien F, Li M, Chen Z, Wilensky R, Matthai W, Qasim A, Hakonarson HH, Devaney J, Burnett MS, Pichard AD, Kent KM, Satler L, Lindsay JM, Waksman R, Epstein SE, Scheffold T, Berger K, Huge A, Martinelli N, Olivieri O, Corrocher R, McKeown P, Erdmann E, Konig IR, Holm H, Thorleifsson G, Thorsteinsdottir U, Stefansson K, Do R, Xie C, Siscovick D. Genome-wide association of earlyonset myocardial infarction with single nucleotide polymorphisms and copy number variants. Nat Genet. 2009; 41(3):334-341. [PubMed: 19198609]

38. Damani SB, Topol EJ. The case for routine genotyping in dual-antiplatelet therapy. J Am Coll Cardiol. 56(2):109-111. [PubMed: 20471193]

39. Maurice CB, Barua PK, Simses D, Smith P, Howe JG, Stack G. Comparison of three commercial CYP2C9/VKORC1 genotyping assays for warfarin sensitivity. Journal of Molecular Diagnostics. 2008; 10(6):566.

40. Gurbel PA, Becker RC, Mann KG, Steinhubl SR, Michelson AD. Platelet function monitoring in patients with coronary artery disease. J Am Coll Cardiol. 2007; 50(19):1822-1834. [PubMed: 17980247]

41. Breet NJ, van Werkum JW, Bouman HJ, Kelder JC, Ruven HJ, Bal ET, Deneer VH, Harmsze AM, van der Heyden JA, Rensing BJ, Suttorp MJ, Hackeng CM, ten Berg JM. Comparison of platelet function tests in predicting clinical outcome in patients undergoing coronary stent implantation. JAMA. 303(8):754-762. [PubMed: 20179285]

42. Gurbel PA, Tantry US, Shuldiner AR, Kereiakes DJ. Genotyping: one piece of the puzzle to personalize antiplatelet therapy. J Am Coll Cardiol. 56(2):112-116. [PubMed: 20471192]

43. Price MJ, Berger PB, Angiolillo DJ, Teirstein PS, Tanguay JF, Kandzari DE, Cannon CP, Topol EJ. Evaluation of individualized clopidogrel therapy after drug-eluting stent implantation in patients with high residual platelet reactivity: design and rationale of the GRAVITAS trial. Am Heart J. 2009; 157(5):818-824. 824, e811. [PubMed: 19376306]

44. Testing platelet reactivity in patients undergoing elective stent placement on clopidogrel to guide alternative therapy with prasugrel (TRIGGER-PCI). [March 30, 2010]. www.clinicaltrials.gov

45. Double randomization of a monitoring adjusted antiplatelet treatment versus a common antiplatelet treatment for DES implantation, and interruption versus continuation of double antiplatelet therapy (ARCTIC). [March 30, 2010]. www.clinicaltrials.gov

46. Gladding P, Webster M, Zeng I, Farrell H, Stewart J, Ruygrok P, Ormiston J, El-Jack S, Armstrong G, Kay P, Scott D, Gunes A, Dahl ML. The pharmacogenetics and pharmacodynamics of clopidogrel response: an analysis from the PRINC (Plavix Response in Coronary Intervention) trial. JACC Cardiovasc Interv. 2008; 1(6):620-627. [PubMed: 19463375]

47. Gladding P, White H, Voss J, Ormiston J, Stewart J, Ruygrok P, Bvaldivia B, Baak R, White C, Webster M. Pharmacogenetic testing for clopidogrel using the rapid INFINITI analyzer: a doseescalation study. JACC Cardiovasc Interv. 2009; 2(11):1095-1101. [PubMed: 19926050]

48. Pena A, Collet JP, Hulot JS, Silvain J, Barthelemy O, Beygui F, Funck-Brentano C, Montalescot G. Can we override clopidogrel resistance? Circulation. 2009; 119(21):2854-2857. [PubMed: 19487603]

49. Hulot JS, Wuerzner G, Bachelot-Loza C, Azizi M, Blanchard A, Peyrard S, Funck-Brentano C, Gaussem P. Effect of an increased clopidogrel maintenance dose or lansoprazole co-administration on the antiplatelet response to clopidogrel in CYP2C19-genotyped healthy subjects. J Thromb Haemost. 8(3):610-613. [PubMed: 20040040] 
50. Wiviott SD, Braunwald E, McCabe CH, Montalescot G, Ruzyllo W, Gottlieb S, Neumann FJ, Ardissino D, De Servi S, Murphy SA, Riesmeyer J, Weerakkody G, Gibson CM, Antman EM. Prasugrel versus clopidogrel in patients with acute coronary syndromes. N Engl J Med. 2007; 357(20):2001-2015. [PubMed: 17982182]

51. Wallentin L, Becker RC, Budaj A, Cannon CP, Emanuelsson H, Held C, Horrow J, Husted S, James S, Katus H, Mahaffey KW, Scirica BM, Skene A, Steg PG, Storey RF, Harrington RA, Freij A, Thorsen M. Ticagrelor versus clopidogrel in patients with acute coronary syndromes. N Engl J Med. 2009; 361(11):1045-1057. [PubMed: 19717846]

52. Steinberg KK, Smith SJ, Stroup DF, Olkin I, Lee NC, Williamson GD, Thacker SB. Comparison of effect estimates from a meta-analysis of summary data from published studies and from a metaanalysis using individual patient data for ovarian cancer studies. Am J Epidemiol. 1997; 145(10): 917-925. [PubMed: 9149663]

53. Bonello L, Camoin-Jau L, Arques S, Boyer C, Panagides D, Wittenberg O, Simeoni MC, Barragan P, Dignat-George F, Paganelli F. Adjusted clopidogrel loading doses according to vasodilatorstimulated phosphoprotein phosphorylation index decrease rate of major adverse cardiovascular events in patients with clopidogrel resistance: a multicenter randomized prospective study. J Am Coll Cardiol. 2008; 51(14):1404-1411. [PubMed: 18387444] 
A.

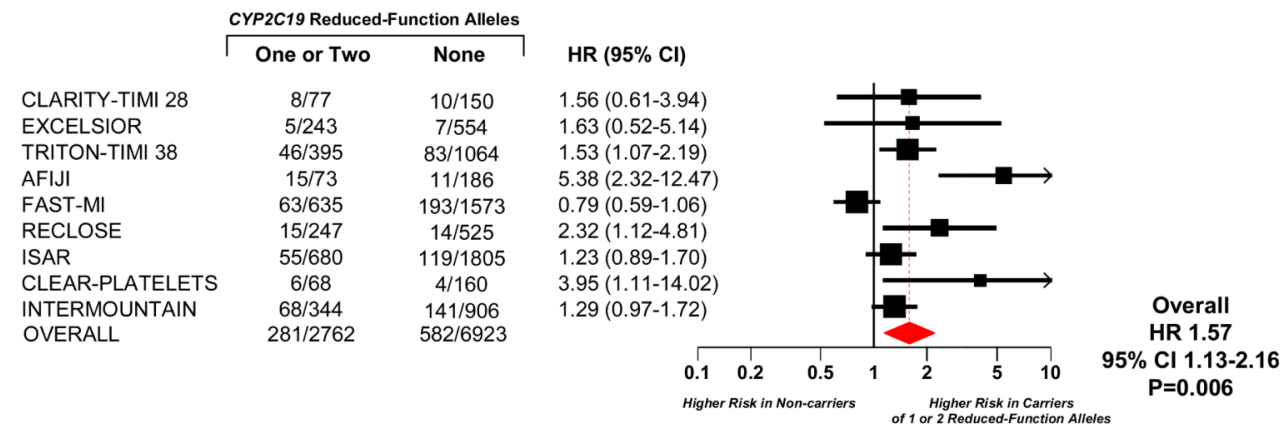

B.

\begin{tabular}{lcc} 
& \multicolumn{2}{c}{ cYP2C19 Reduced-Function Alleles } \\
\cline { 2 - 3 } & One & None \\
& & \\
CLARITY-TIMI 28 & $8 / 73$ & $10 / 150$ \\
EXCELSIOR & $5 / 226$ & $7 / 554$ \\
TRITON-TIMI 38 & $42 / 357$ & $83 / 1064$ \\
AFIJI & $13 / 64$ & $11 / 186$ \\
FAST-MI & $53 / 577$ & $193 / 1573$ \\
RECLOSE & $13 / 221$ & $14 / 525$ \\
ISAR & $52 / 633$ & $119 / 1805$ \\
CLEAR-PLATELETS & $5 / 63$ & $4 / 160$ \\
INTERMOUNTAIN & $65 / 330$ & $141 / 906$ \\
OVERALL & $256 / 2544$ & $582 / 6923$
\end{tabular}

$\mathrm{HR}(95 \% \mathrm{Cl})$

$1.64(0.65-4.17)$

$1.75(0.56-5.53)$

$1.55(1.07-2.25)$

$5.42(2.23-13.18)$

$0.73(0.54-0.99)$

$2.25(1.06-4.78)$

$1.25(0.90-1.73)$

$3.45(0.93-12.89)$

$1.29(0.96-1.73)$

Overall

\% CI 1.11-2.17

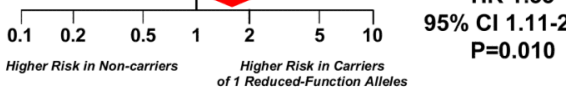

C.

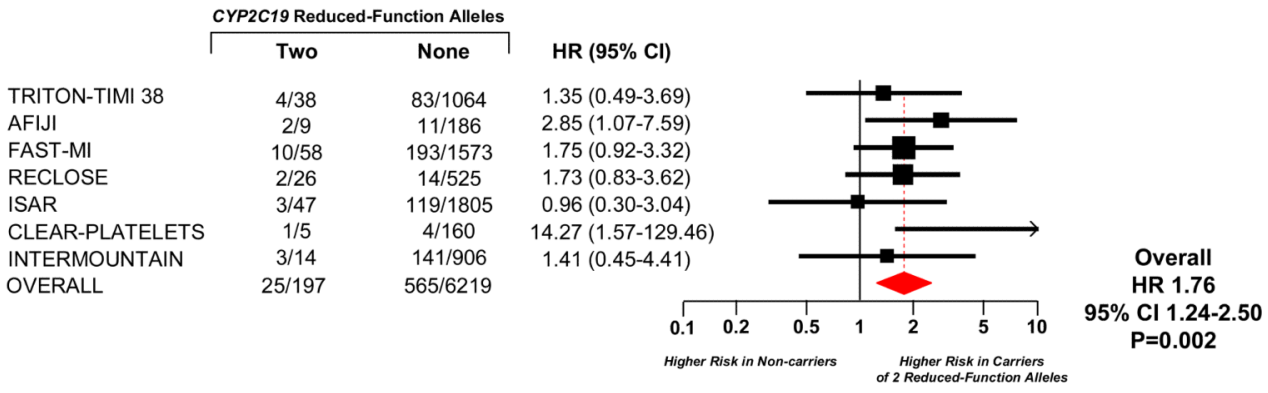

Figure 1. Cardiovascular Death, Myocardial Infarction, or Ischemic Stroke by CYP2C19 Genotype

Among patients treated with clopidogrel, hazard ratios are reported for cardiovascular death, myocardial infarction, or ischemic stroke among carriers of one or two (Panel A), one (Panel B), or two (Panel C) CYP2C19 reduced-function alleles versus non-carriers. Squares with horizontal lines represent the hazard ratio and corresponding $95 \%$ confidence intervals, and the size of each square reflects the statistical weight of the study in the meta-analysis. The diamond represents the $95 \%$ confidence for the overall hazard ratio. The number of events and the number of individuals at risk for events is presented for each study. In Panel C, studies that had no adverse cardiovascular events among carriers of two reduced-function CYP2C19 alleles could not be included in the analysis.

A. Carriers of One or Two CYP2C19 Reduced-Function Alleles versus Non-Carriers

B. Carriers of One CYP2C19 Reduced-Function Alleles versus Non-Carriers 
C. Carriers of Two CYP2C19 Reduced-Function Alleles versus Non-Carriers 
A.

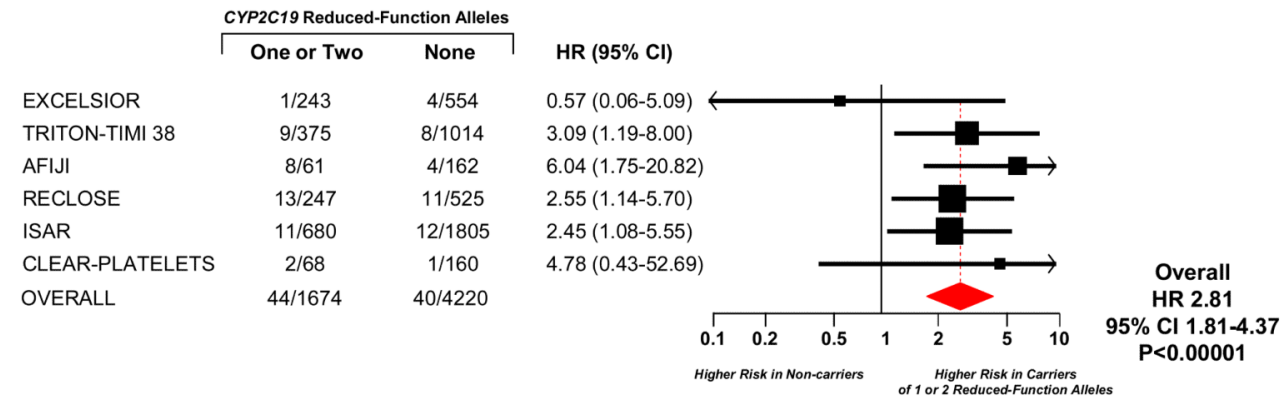

B.

\begin{tabular}{lcc|} 
& \multicolumn{2}{c}{ CYP2C19 Reduced-Function Alleles } \\
\cline { 2 - 3 } & One & None \\
EXCELSIOR & $1 / 226$ & $4 / 554$ \\
TRITON-TIMI 38 & $7 / 339$ & $8 / 1014$ \\
AFIJI & $7 / 53$ & $4 / 162$ \\
RECLOSE & $11 / 221$ & $11 / 525$ \\
ISAR & $10 / 633$ & $12 / 1805$ \\
CLEAR-PLATELETS & $1 / 63$ & $1 / 160$ \\
OVERALL & $37 / 1535$ & $40 / 4220$
\end{tabular}

HR $(95 \% \mathrm{Cl})$

$0.61(0.07-5.44)$

$2.65(0.96-7.30)$

$7.75(2.10-28.60)$

$2.41(1.05-5.55)$

$2.39(1.03-5.54)$

$2.57(0.16-40.99)$

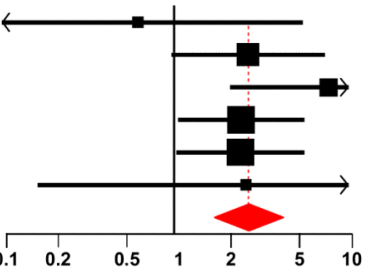

Overall

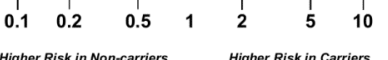

HR 2.67

Higher Risk in Non-carriers $\begin{gathered}\text { Higher Risk in Carriers } \\ \text { of } 1 \text { Reducod-Function Alleles }\end{gathered}$

$\mathrm{P}<0.0001$

C.

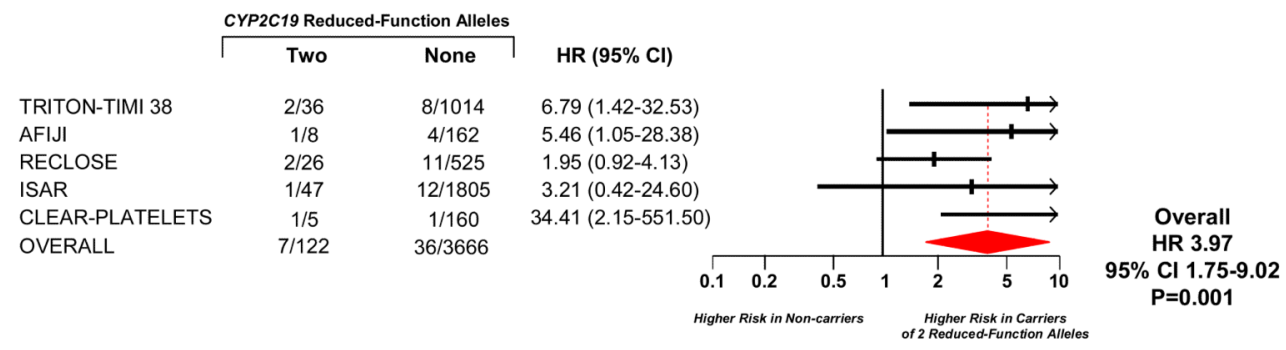

Figure 2. Stent Thrombosis by CYP2C19 Genotype

Among patients treated with clopidogrel, hazard ratios are reported for stent thrombosis among carriers of one or two (Panel A), one (Panel B), or two (Panel C) CYP2C19 reducedfunction alleles versus non-carriers. Squares with horizontal lines represent the hazard ratio and corresponding $95 \%$ confidence intervals, and the size of each square reflects the statistical weight of the study in the meta-analysis. The diamond represents the $95 \%$ confidence for the overall hazard ratio. The number of events and the number of individuals at risk for events is presented for each study. In Panel C, studies that had no stent thrombosis events among carriers of two reduced-function CYP2C19 alleles could not be included in the analysis.

A. Carriers of One or Two CYP2C19 Reduced-Function Alleles versus Non-Carriers

B. Carriers of One CYP2C19 Reduced-Function Alleles versus Non-Carriers

C. Carriers of Two CYP2C19 Reduced-Function Alleles versus Non-Carriers 
Cardiovascular Death, Myocardial Infarction, or Stroke

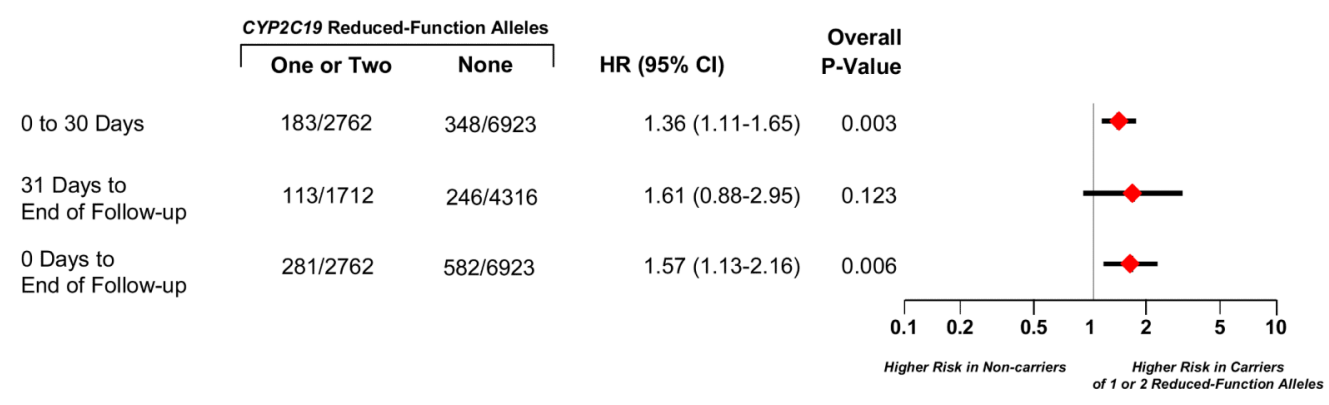

Stent Thrombosis

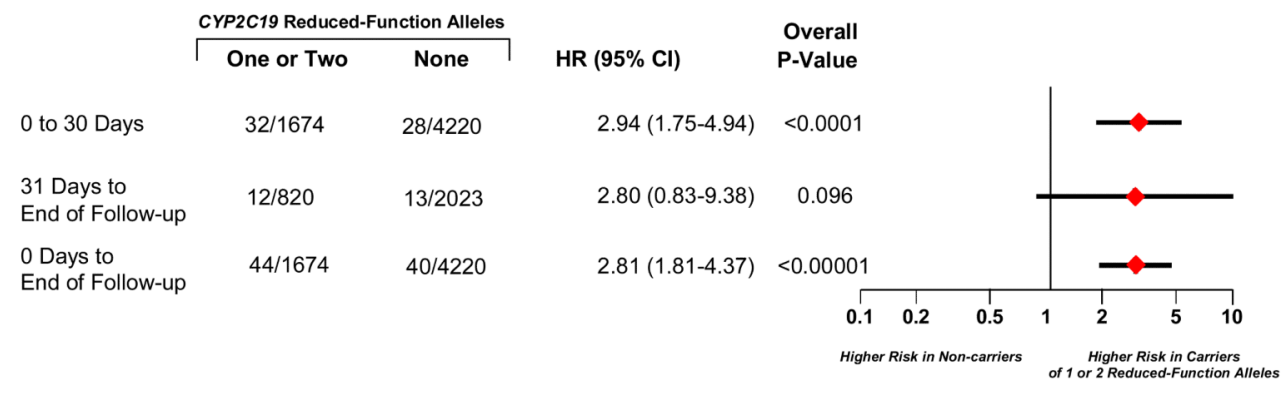

Figure 3. Timing of Events for Cardiovascular Death, Myocardial Infarction, or Ischemic Stroke and Stent Thrombosis

Among patients treated with clopidogrel, hazard ratios are reported for cardiovascular death, myocardial infarction, or ischemic stroke and for stent thrombosis among carriers of one or two $C Y P 2 C 19$ reduced-function alleles versus non-carriers. Diamonds with horizontal lines represent the hazard ratio and corresponding $95 \%$ confidence intervals across the different timepoints. Nine studies contributed to the endpoint of cardiovascular death, myocardial infarction, or stroke from 0 to 30 days, and six studies from 31 days to end of follow-up. Analogously, six studies contributed to the endpoint of stent thrombosis from 0 to 30 days, and three studies from 31 days to end of follow-up. The number of events and the number of individuals at risk for events is presented for each study. In the analysis, a patient could have had a non-fatal event during 0 to 30 days and a subsequent event after day 30 . 


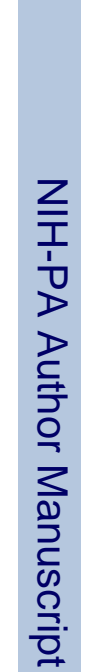

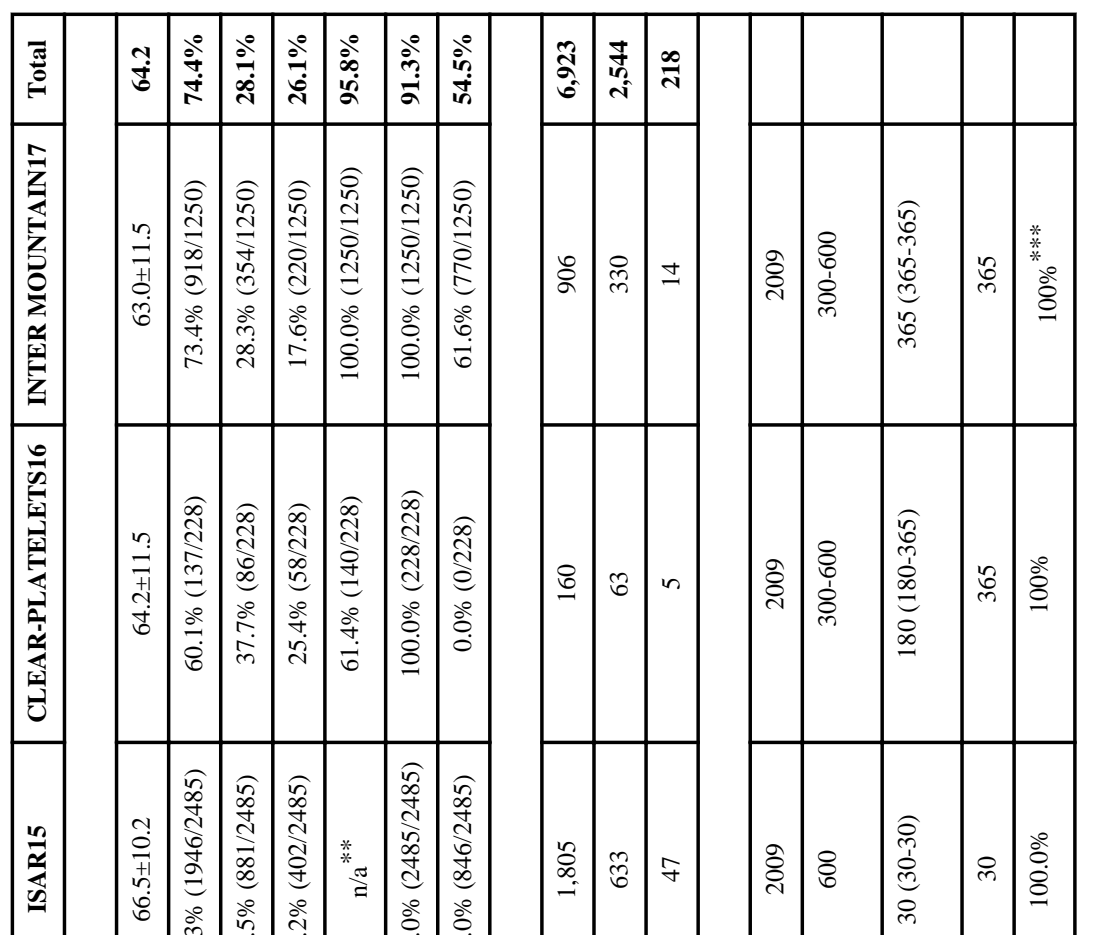

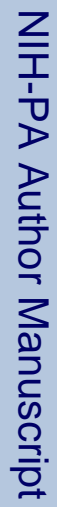

\begin{tabular}{l}
\hline \\
\hline \\
0 \\
0 \\
0 \\
\hline \\
\hline
\end{tabular}

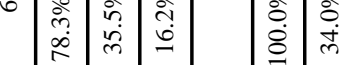

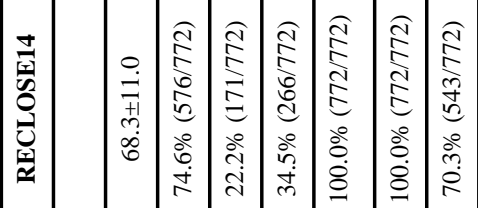
率

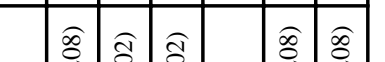

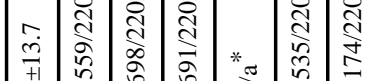

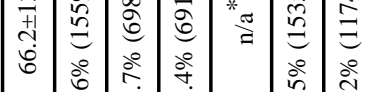

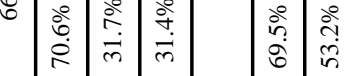

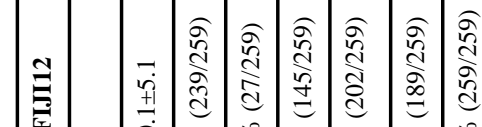

$\geq \quad \frac{0}{\circ}$ ๘

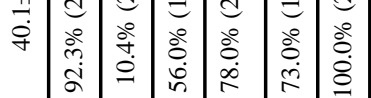

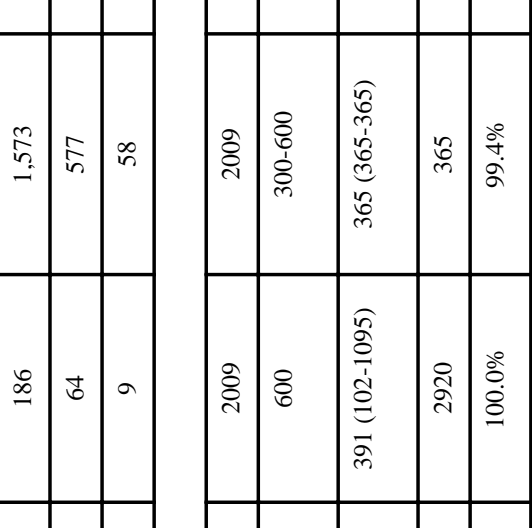

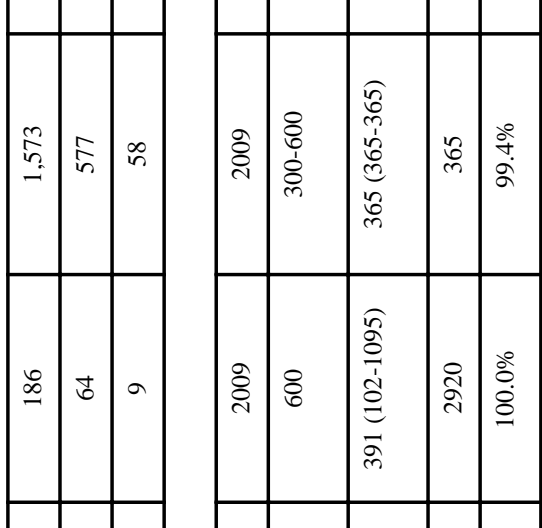

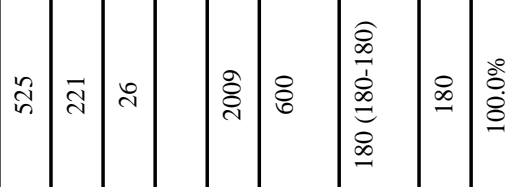

ב

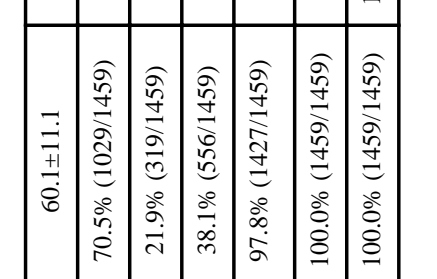

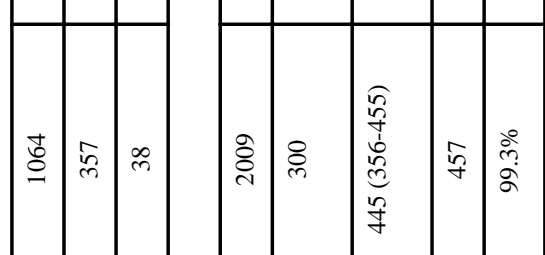

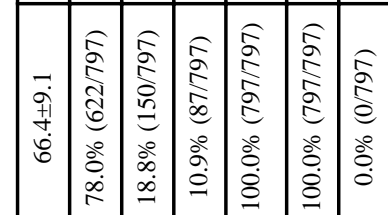

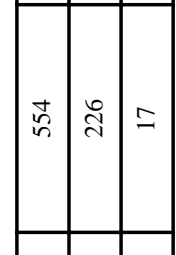

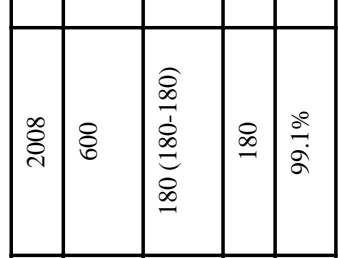

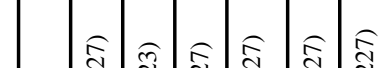

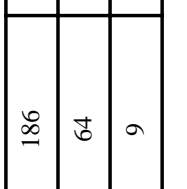


Table 2

Pooled Baseline Characteristics by CYP2C19 Genotype Status

\begin{tabular}{|l|c|c|c|c|}
\hline & & \multicolumn{3}{|c|}{ CYP2C19 Reduced-Function Alleles } \\
\hline & $\begin{array}{c}\text { Overall } \\
\text { (N=9685) }\end{array}$ & $\begin{array}{c}\text { None } \\
(\mathbf{N = 6 9 2 3})\end{array}$ & $\begin{array}{c}\text { One } \\
(\mathbf{N = 2 5 4 4})\end{array}$ & $\begin{array}{c}\text { Two } \\
(\mathbf{N = 2 1 8})\end{array}$ \\
\hline Weighted Age (yrs) & 64.2 & 64.1 & 64.6 & 63.7 \\
\hline Male Sex & $7204(74.4 \%)$ & $5180(74.8 \%)$ & $1852(72.8 \%)$ & $172(78.9 \%)$ \\
\hline Diabetes & $2724(28.1 \%)$ & $1926(27.8 \%)$ & $739(29.0 \%)$ & $58(27.1 \%)$ \\
\hline Current Smoker & $2524(26.1 \%)$ & $1821(26.3 \%)$ & $648(25.5 \%)$ & $55(25.2 \%)$ \\
\hline ACS at Presentation & $5278(54.5 \%)$ & $3820(55.2 \%)$ & $1339(52.6 \%)$ & $119(54.6 \%)$ \\
\hline PCI at Presentation & $8847(91.3 \%)$ & $6336(91.5 \%)$ & $2316(91.0 \%)$ & $195(89.4 \%)$ \\
\hline White Race* & $4781(95.8 \%)$ & $3399(95.9 \%)$ & $1277(95.7 \%)$ & $105(92.9 \%)$ \\
\hline
\end{tabular}

Age presented as a weighted mean; the other data is presented as $\mathrm{n}(\%)$. There were no significant differences for the categorical variables across CYP2C19 genotype. ACS indicates acute coronary syndrome; PCI, percutaneous coronary intervention.

* Data on race (self-reported) was not captured uniformly in ISAR and FAST-MI; therefore the denominator for the overall, none, one, and two CYP2C19 reduced-function allele groups is 4992, 3545, 1334, and 113. 